\title{
Spot Urine Protein: Creatinine Ratio as Risk Factor in Relapsing Nephrotic Syndrome
}

\author{
Dr. D. Rajkumar M.D ${ }^{1}$,Dr. S. Murugesalakshmanan M.D. ${ }^{2}$, \\ Dr. A. Subasakthi, $\mathrm{MD}^{3}$,Dr. D. S. Balasankar M.D. DCH. ${ }^{4}$, \\ ${ }^{1}$ Assistant Professor of Paediatrics, Madurai Medical college, Madurai \\ ${ }^{2}$ Assistant Professor of Paediatrics, Madurai Medical college, Madurai \\ ${ }^{3}$ Senior Resident, Madurai Medical college, Madurai \\ ${ }^{4}$ Professor of Paediatrics, Madurai Medical college, Madurai.
}

\begin{abstract}
Background: Nephrotic Syndrome is a common childhood illness. Major problem with this disease is frequent relapse. So, it is important to identify the children at risk for relapses to treat and further follow up.

Aim \&Objective: Aim of present study was to determine Spot PCR is a strong indicator of relapse in Nephrotic Syndrome. The primary objective of study was to determine the correlation between acute phase Spot PCR and subsequent relapses in Nephrotic Syndrome.

Material and Method of study: Sixty two Nephrotic Syndrome children were included in this prospective cohort study at ICH\&RC Madurai Medical College \& Hospital. Spot PCR was estimated at the acute phase of disease before starting steroid therapy. They were followed up for six months from the time of remission to determine the further relapse.

Results: A total of sixty two children were enrolled of whom two were excluded. Among the cases excluded, one children had steroid resistant Nephrotic Syndrome, one child was lost to follow up. Among, 60 included children, 20 cases had their first episodes and 40 cases were infrequent relapsers. In our study Spot PCR level for Relapsers $20.97 \pm 10.44 \mathrm{mg} / \mathrm{mg}$ and for non -relapsers $14.94 \pm 8.74 \mathrm{mg} / \mathrm{mg}$. High level of Spot PCR at acute phase of Nephrotic syndrome was a risk factor for relapse with Adjusted OR 1.09, significance 0.014 and 95\% CI of OR 1.02,1.17.

Conclusion: Proteinuria has prognostic significance for renal diseases. Severity of Renal involvement in Nephrotic syndrome was determined by level of proteinuria. Significantly elevated level of Spot PCR at acute phase of disease is a predictor of further relapses in Nephrotic syndrome.
\end{abstract}

Keywords: Nephrotic syndrome, Spot PCR, steroid therapy.

\section{Introduction}

Nephrotic syndrome is the principal presentation of the Renal disease, reflecting the pathophysiologic effect of urinary losses of large quantities of protein. Nephrotic syndrome characterized by proteinuria $>40 \mathrm{mg} / \mathrm{m}^{2} / \mathrm{h}$, hypoalbuminemia $<2.5 \mathrm{mg} / \mathrm{dl}$, edema and hypercholesterolemia. The proteinuria is relatively selective, primarly constitute albumin. Nephrotic syndrome is reported to be $2-3 / 100,000$ children per year ${ }^{1}$. The persistence and severity of lipid changes in serum correlates well with duration and frequency of relapses. The intensity of hyperlipidemia is usually related to the severity of proteinuria ${ }^{2}$. The protein creatinine ratio is measured to check the level at which the kidneys are functioning ${ }^{3}$.

Urine protein estimation by $24 \mathrm{hr}$ collection is a difficult task with many errors including incomplete collection, incorrect timing, incomplete bladder voiding and bacterial growth. As creatinine excretion is fixed and its concentration in urine varies with hydration status, Spot protein creatinine ratio nullifies the effect of hydration on protein estimation. Random urine collection is simple $\boldsymbol{\&}$ can be done at any time of the day preferably in the morning. A test for quantification of urinary protein excretion in term of protein: creatinine ratio can be performed to predict accurately the level of proteinuria and relavent to asses the prognosis and treatment of renal disease.(caring for Australians with Renal Impairment Guidelines,2004 ).

Hence we have planned to perform a study to asses prognosis and relapses of Nephrotic Syndrome by assessing Spot PCR.

\section{Methodology}

The prospective cohort study was conducted over one year duration, August 2013-July 2014 at ICH \&RC, Madurai medical college, Madurai. The study participants included the children who were admitted as inpatient for the management of Nephrotic syndrome at paediatric ward. Children presented with first episode and infrequent Relapsers in whom steroid therapy was not yet started were included in the study. However , 
children who were suffering from Frequent Relapses, Steroid Dependent, Steroid Resistant and Secondary Nephrotic Syndrome were excluded from our study. Parental consent and ethical committee approval were obtained. Detailed clinical history was elicited and a through clinical examination was performed. Baseline blood investigations, 24 hours urinary protein, Spot Protein : creatinine ratio, serum albumin, lipid profile , urine albumin, urine culture and sensitivity, USG abdomen and pelvis, chest X ray \& TB screening were performed.

\section{Spot Protein: creatinine ratio estimation:}

Early morning urine sample was obtained before starting steroid therapy and urinary protein was estimated by Biuret method and creatinine is measured by jaffe's reaction ${ }^{4}$. The Spot PCR was calculated by $\mathrm{mg} / \mathrm{mg}$. cut off value of Spot PCR in Nephrotic syndrome children is $>2$. Normal value is $<0.5$ for children aged $<2$ years and $<0.2$ for children $>2$ years.

Follow up: Spot PCR sample was calculated at the acute phase of disease before starting steroid therapy, and they were followed up once in every two weeks at the paediatric nephrology OP for six months period from the time of remission to detect further relapses.

\section{Data analysis}

Data were analyzed using SPSS 11.2 software version. The association between spot PCR and relapses were analyzed using chi-square test and t-test. Binary logistic regression was used for the predictor of relapse.

\section{Results}

A total of 62 cases were enrolled of whom two cases were excluded because one child became Steroid Resistant and another one child was lost for follow up. Among 60 children, 20 cases had their First Episodes and 40 were Infrequent Relapsers. 45 patients (75\%) attained remission in <2 weeks while ten children (25\%) took $>2$ weeks to attain remission.

$80 \%$ of the children presenting with Nephrotic Syndrome belonged to 1-6 years of age with males being predominantly affected. The precipitating factors included Acute respiratory infection and urinary tract infection in $35 \%$ and $21 \%$ of the children respectively, while it was unknown for $44 \%$ of the cases. 12 patients found to have culture positive urinary tract infection. Klebsiella (58\%) was isolated most commonly in children, while E.coli and proteus were isolated in 3 and 2 children respectively.

Among the presenting symptoms edema was the most common (100\%) followed by oliguria $(83 \%)$. Ascites presented in $60 \%$ of children, pallor presented in $38 \%$ of children. Sulphosalicylic acid test was used to test urinary proteinuria. It was observed that $25 \%$ presented with moderate and $75 \%$ presented with severe proteinuria. Mean 24 hours urinary protein ranged from 0.8 to $4 \mathrm{~g} / \mathrm{dl}$ with mean value (2g/dl).serum Albumin ranged between 1.35 to $2.7 \mathrm{~g} / \mathrm{dl}$ with mean value of $1.9 \mathrm{~g} / \mathrm{dl}$. Mild, Moderate , and Severe Hypoalbuminemia were seen in $20 \%, 47 \%, 33 \%$ children respectively. In this study $75 \%$ of the children attained remission between 2 weeks to 5 weeks duration. Among 25 children were relapsed 8 children were those with First Episode Of Nephrotic Syndrome.

Table 1:-Comparison of baseline characteristics between the Relapsers and Non- relapsers

\begin{tabular}{|l|l|l|l|l|}
\hline Characteristic & Non-relapser & Relapser & Tstatistic & P value \\
\hline Age & $4.87 \pm 2.67$ & $5.71 \pm 2.48$ & -1.26 & 0.23 \\
\hline Duration of illness & $5.97 \pm 4.32$ & $13.66 \pm 29.12$ & -1.58 & 0.12 \\
\hline Serum urea & $24.4 \pm 7.23$ & $24.7 \pm 8.8$ & -0.14 & 0.900 \\
\hline Serum creatinine & $0.703 \pm 0.13$ & $0.71 \pm 0.135$ & -0.17 & 0.87 \\
\hline Serum Albumin & $1.924 \pm 0.38$ & $1.761 \pm 0.40$ & 1.48 & 0.144 \\
\hline 24hr urinary protein & $1746.7 \pm 697.10$ & $2018.09 \pm 958.18$ & -1.260 & 0.219 \\
\hline Spot PCR & $14.94 \pm 8.74$ & $20.97 \pm 10.44$ & -2.451 & $0.018^{* *}$ \\
\hline
\end{tabular}

**p $<0.05$ was considered to be statistically significant

Table 1 shows the comparison of baseline charecteristics between the Relapsers and Non-relapsers which were comparable. Spot Protein:Creatinine Ratio was significantly different between Relapsers and Non-relapsers.

Table 2:- Acute phase lipid abnormalities in Relapsers and Non-relapsers

\begin{tabular}{|l|l|l|l|l|}
\hline Lipids & Non relapsers & Relapsers & Chi square & P value \\
\hline Hypercholesterolemia & $35(100)$ & $25(100)$ & - & - \\
\hline Hypertriglyceridemia & $34(97.3)$ & $23(95.7)$ & 0.119 & 0.730 \\
\hline High LDL & $33(94.6)$ & $23(95.7)$ & 0.033 & 0.922 \\
\hline High LDL:HDL & $26(70.3)$ & $19(82.6)$ & 1.152 & 0.283 \\
\hline
\end{tabular}

**p<0.05 was considered to be statistically significant 
In the acute phase, there were no statistical significant differences between the lipid abnormalities manifested by the Relapsers and Non relapsers.

Table 3:-Significance of Spot Protein : Creatinine Ratio

\begin{tabular}{|l|l|l|l|l|l|}
\hline Predictors & Adjusted OR & SE & Z & Significance & 95\% CI of OR \\
\hline Spot PCR & 1.09 & 0.39 & 2.45 & 0.014 & $1.02,1.17$ \\
\hline
\end{tabular}

Table 3 shows further, on performing logistic regression analysis, spot PCR (adjusted $\mathrm{OR}=2.45$, $\mathrm{p}=0.014$ ) was found to be statistically significant. So, during acute phase Spot PCR was a good predictor of relapses in Nephrotic Syndrome children.

\section{Discussion}

The amount of protein excreted in urine has diagnostic and prognostic significance and it is also used to asses effectiveness of urinary creatinine excretion in the presence of a stable GFR. If GFR is fairly constant in a given patient, it can be reasoned that if the protein excretion rate were likewise fairly stable during a day, a simple ratio of the concentration of urinary protein and creatinine in a single voided urine sample, would reflect the cumulative protein excretion over a day as the ratio of two stable rates would cancel out time factor ${ }^{5}$. Degree of proteinuria reflects the progression of renal disease which helps in assessing prognosis of renal disease which affecting the normal Renal functions (Caring for Australians with Renal impairment Guidelines,2004). Estimation of protein in urine is used for not only monitoring prognosis but also for treatment purposes.

Traditionally, the assessment of proteinuria is done by collecting a 24-hours urine sample to measure the amount of protein excreted in mg per 24 hours. This method is fairly accurate but become unreliable due to the problem of 24-hours urinary samples which is never reliable. Also, the collection time is too long for the patient's patience ${ }^{6}$. Protein: Creatinine ratio measurements on a single-voided specimen provide a convenient and reliable alternative method than 24-hours urine measurements. [Caring for Australians with Renal Impairment (CARI) Guidelines, 2004 and Amir Said Alizadeh Naderi, MD and Robert F. Reilly, MD, 2008]. In the present study Spot PCR was estimated at the time of admission before starting steroid therapy. These children were followed up for six months to look for further relapse. Most of the children in our study belonged to $1-6$ years $(80 \%)$ while $20 \%$ of the children belonged to $6-12$ years of age ${ }^{14,15}$. Male :Female ratio of the present study was $2: 1$, it was comparable to MN sarker et al,2005 study showed that $67 \%$ of children belonged to 2-6 years age group with male to female sex ratio roughly $2: 1^{7}$.

Subsequent relapse for Nephrotic Syndrome were commonly triggered by ARI(35\%), other usual factor is UTI (21\%). These findings were concurrent with Kasim et al study ${ }^{8}$. In this present study edema $100 \%$ present in Nephrotic Syndrome it was comparable to Shah et al study ${ }^{9}$. Oliguria was a presentation for $83 \%$ of children, it was comparable to Balgopal et al study ${ }^{10}$.In this present study severe and moderate proteinuria children were respectively $75 \%, 25 \%$. Shah et al reported $74 \%$ and $26 \%$ of children had severe and moderate proteinuria respectively ${ }^{9}$. In the present study, the overall mean serum Albumin value was $1.85 \mathrm{~g} / \mathrm{dl}$. This was comparable with the reports of Bhandari et al study who reported serum Albumin levels of $1.85 \pm 0.52 \mathrm{~g} / \mathrm{dL}{ }^{11}$.

Serum Albumin ranged between 1.35 to $2.7 \mathrm{~g} / \mathrm{dl}$ with mean value of $1.9 \mathrm{~g} / \mathrm{dl}$. Mild, Moderate, Severe Hypoalbuminemia were seen in $20 \%, 47 \%, 33 \%$ children respectively. In this study $75 \%$ children attained remission between 2 weeks to 5 weeks duration. Among 25 children who relapsed 8 children were those with first episode of Nephrotic Syndrome. Correlation between serum Albumin and serum cholesterol at the acute phase of the disease was performed and it revealed a statistically significant inverse relation $(p<0.01)$ between them in the present study but had positive correlation with proteinuria $(\mathrm{p}<0.01)$. Om P Mishra et al also observed a significant negative correlation between plasma lipids concentration and Albumin and observed positive correlation with plasma lipids and proteinuria ${ }^{12}$. In the present study, $83 \%$ of children attained remission within 2 weeks. These results were concurrent with those of Priya Pais et al, where 80 to $90 \%$ of children responded to corticosteroid therapy within 3 weeks ${ }^{13}$.

On performing logistic regression analysis, spot PCR (adjusted $\mathrm{OR}=2.45, \mathrm{p}=0.014$ ) was found to be significant predictors of relapse. Among Relapsers, all of them had single relapse during six months of follow up. They seem to follow infrequent relapse course.

\section{Limitation}

The present study had few limitations to be noted. Factors which affect creatinine excretion in urine like age, sex, muscle mass also affect the Spot PCR. Also the changes in Spot PCR response to therapy during follow up have to be studied further. 


\section{Conclusion}

1. Spot PCR is a simple and convenient method for predicting relapse in children with Nephrotic syndrome.

2. Significantly elevated level of Spot PCR at acute phase of disease is a predictor of further relapses in Nephrotic syndrome.

\section{Recommendation}

Future studies are needed to determine the cut off level of Spot PCR to determine further relapses in Nephrotic Syndrome children.

\section{Bibliography}

[1]. Nash MA, Edelmann CM,Bernstein J, Barnett HL. The nephrotic syndrome volume II

[2]. Pediatric kidney disease, $2^{\text {nd }}$ edition. Boston: Little Brown and company 1991;1247-1266.

[3]. Srinivastava RN,Aravind Bagga.Paediatric nephrology. $4^{\text {th }}$ edition. New Delhi, India: Jaypee brothers, medical publishers (P) Ltd;2005.p.161-200.

[4]. Tietz, 2008 6th ed. and McIntyre, Natasha J; Taal, Maarten W, 2008. kolmer JA, Spaulding EH, Robinson HN. Methods for estimation of urine. Approved laboratory technique, $5^{\text {th }}$ edition. New york: Appleton century crafts Inc 1951; $138-144$.

[5]. Grinsberg JM,Chang BS,Matarese RA. Use of single voided urine samples to estimate quanti tative proteinuria. N Eng J Med 1983; 309; 1543-1546.

[6]. Amir Said Alizadeh Naderi, MD and Robert F. Reilly, MD, 2008

[7]. MN Sarker, MMSU Islam, T Saad, FN Shoma, LS Sharmin, HA Khan, F Afrooz, LE Fatmi,A Alam, ASM Salimullah, MR Uddin, T Saha.

[8]. Kasim rani, Adel Abdul salam AL- Badri,childhood nephrotic syndrome frequent and Infrequent relapses and risk fectros for relapse. (Pub med).

[9]. Shah, Betkerur. Nephrotic syndrome in childhood. Indian J Med Asso 1969;52:215-8.

[10]. Balgopal R, Krishnan S, Vijaya. Nephrotic syndrome in children. Antiseptic 1974; 71:1-7.

[11]. Kannan et al serum cholesterol, lipoprotein \& risk of CHD. The Framingham study. annintern med 1974: 74

[12]. Om P Mishra, Ranjiti Prasad, Divya Atri,Surya K Singh and Zildedar Ali. Journal of pediatric Biochemistry, Vol 2, No.31pp,159162,2012

[13]. Robert M.Kliegman MD, priya pais , ellso, Among, Ellis D.Avner Nelson Text of Pediatrics . 19 th $^{\text {th }}$ Edition. P 1801-1806

[14]. Katiyar GP Singh, Agarwal. Study of serum lipid pattern in nephrotic syndrome in children. Indian Paediatrics 1976; 13:83-7.

[15]. Malhotra ML, Andurkkar GP. Clinical biochemical histological correlation in nephroticsyn drome in children. Indian J Paediatr 1976; $43: 153$ 